\title{
PERBEDAAN KEKUATAN TRANSVERSAL BASIS RESIN AKRILIK POLIMERISASI PANAS PADA PERENDAMAN MUNUMAN BERALKOHOL DAN AQUADES
}

\author{
${ }^{1}$ Felicia P. C. C. Pantow \\ ${ }^{2}$ Krista V. Siagian \\ ${ }^{3}$ Damajanty H. C. Pangemanan
}

\author{
${ }^{1}$ Kandidat Skripsi Program Studi Pendidikan Dokter Gigi Fakultas Kedokteran \\ ${ }^{2}$ Program Studi Pendidikan Dokter Gigi Fakultas Kedokteran \\ ${ }^{3}$ Bagian Fisiologi Fakultas Kedokteran \\ Universitas Sam Ratulangi Manado \\ Email: pantowfelicia@gmail.com
}

\begin{abstract}
Material denture base that is often used is the acrylic resin thermal polymerization. Thermal polymerized acrylic base material is easily fractured when it is knocked down and easily absorbs liquids such as alcohol. Consumption of alcohol increases the plasticization effects of materials through the process of diffusion and causes crazing in acrylic resin, thereforre, the resin acrylic becomes easily fractured. This study aimed to measure the lifetimes of objects against fracture and to measure the strength of transversal load maximum acceptable thermal polymerization of acrylic resin upon receiving pressure. This was a laboratory experimental study with a post test only control group design. The acrylic resin plate was used as sample of thermal polymerization with a size of $65 \times 10 \times 2.5 \mathrm{~mm}$ for testing the strength of the transversal load. There were a total of 32 samples consisting of 16 samples for groups soaked in liquor and 16 samples for groups soaked in aquades for 8 days. Each sample was tested for the strength of the transversal load. Data were analyzed with the independent sample t-test to find out the difference between transversal strength of the group soaked in alcohol and the group soaked in aquades. The results showed that the average strength of transversal groups soaked in liquor was $117.35 \mathrm{~N} / \mathrm{mm}^{2}$ and the average strength of groups soaked in aquades was $131.11 \mathrm{~N} / \mathrm{mm}^{2}$. Conclusion: There was a significant difference in the strength of the acrylic resin polymerization transversal thermal soaked in liquor and of that soaked in aquades (P value 0.007).
\end{abstract}

Keywords: alcoholic beverages, aquades, strength transversal

\begin{abstract}
Abstrak: Bahan dasar basis gigi tiruan yang sering digunakan ialah resin akrilik polimerisasi panas. Bahan basis akrilik polimerisasi panas bersifat mudah patah bila terjatuh dan mudah menyerap cairan seperti alkohol. Alkohol yang dikonsumsi pengguna gigi tiruan menyebabkan meningkatkanya efek plasticization dari bahan melalui proses difusi dan menyebabkan crazing pada resin akrilik sehingga resin akrilik mudah fraktur. Untuk mengukur daya tahan benda terhadap fraktur maka dilakukan pengujian kekuatan transversal untuk mengukur beban maksimal yang dapat diterima resin arkilik polimerisasi panas pada saat menerima tekanan. Penelitian ini ialah eksperiman laboratoris dengan post test only control group design. Sampel ialah pelat resin akrilik polimerisasi panas dengan ukuran $65 \times 10 \times 2,5 \mathrm{~mm}$. Jumlah total sampel sebanyak 32 yang terdiri dari 16 sampel untuk kelompok yang direndam dalam minuman beralkohol dan16 sampel untuk kelompok yang direndam dalam aquades selama 8 hari. Setiap sampel dilakukan pengujian kekuatan transversal kemudian dianalisis dengan uji independent sample t-test untuk mengetahui adanya perbedaan kekuatan transversal antara kelompok yang direndam dalam minuman beralkohol dan kelompok yang direndam dalam aquades. Hasil
\end{abstract}


penelitian menunjukkan bahwa rerata kekuatan transversal kelompok yang direndam dalam minuman beralkohol yaitu 117,35 $\mathrm{N} / \mathrm{mm}^{2}$ dan rerata kekuatan transversal keompok yang direndam dalam aquades yaitu $131,11 \mathrm{~N} / \mathrm{mm}^{2}$. Simpulan: Terdapat perbedaan bermakna antara kekuatan transversal resin akrilik polimerisasi panas yang direndam dalam minuman beralkohol dan yang direndam dalam aquades $(\mathrm{P}=0,007)$.

Kata kunci: minuman beralkohol, aquades, kekuatan transversal

Gigi tiruan merupakan suatu benda yang digunakan untuk menggantikan gigi yang sudah hilang. Gigi tiruan lepasan merupakan gigi tiruan yang menggantikan gigi yang hilang dan dapat dilepas oleh pasien sendiri. Gigi tiruan lepasan dipakai karena ekonomis dan pembuatannya mudah. Bahan dasar basis gigi tiruan akrilik yang sering dipakai yaitu resin akrilik polimetil metakrilat yang heat cured atau resin akrilik polimerisasi panas. ${ }^{1}$

Bahan basis akrilik polimerisasi panas memiliki beberapa kekurangan yaitu mudah patah apabila terjatuh, mudah mengalami perubahan warna, porus dan mudah menyerap cairan baik air maupun bahan kimia serta sisa makanan, maupun bahan kimia contohnya alkohol, etanol dan larut dalam cairan kimia. Gigi tiruan dapat terjadi patah yang disebabkan oleh benturan (impact) apabila terjatuh pada permukaan yang kasar, dan tekanan transversal atau fleksural pada basis gigi tiruan selama proses pengunyahan. ${ }^{2}$

Kekuatan transversal adalah daya tahan benda terhadap beban yang diterima. Uji kekuatan transversal dapat memberikan gambaran tentang ketahanan benda dalam menerima beban pada waktu pengunyahan. Kekuatan transversal basis gigi tiruan tergantung dari teknik pengadukan, kandungan monomer sisa, mikroporositas gigi tiruan yang tidak terlihat, jarak waktu dari tahap pengisian ke dalam mould sampai pengepresan, dan jarak waktu dari proses pengepresan hingga proses curing.

World Health Organization memperkirakan bahwa ada sekitar 1/3 penduduk dunia yang mengkonsumsi minuman beralkohol dan 76,3 juta jiwa diantaranya memiliki ketergantungan pada alkohol. ${ }^{3}$ Minuman beralkohol Cap tikus adalah jenis cairan berkadar alkohol rata-rata $40 \%$ yang dihasilkan melalui penyulingan tuak atau saguer (cairan berwarna putih yang keluar dari mayang pohon enau atau seho dalam bahasa daerah Minahasa). Masyarakat Sulawesi Utara suka mengonsumsi minuman beralkohol cap tikus dengan kandungan alkohol 40\% hampir disetiap pesta dan acara adat di Sulawesi Utara. ${ }^{4}$ Dari sekian banyak peminum alkohol yang rata-rata berusia remaja sampai lanjut usia, ada yang kehilangan gigi dan memakai gigi tiruan. Kandungan alkohol yang terdapat dalam minuman beralkohol yang dikonsumsi oleh pemakai gigi tiruan diduga dapat memengaruhi daya tahan gigi tiruan terhadap patahnya gigi tiruan. Berdasarkan penelitian oleh Umaiyal S. tahun 2011 bahwa ada perbedaan yang signifikan terhadap kekuatan transversal pada resin akrilik polimerisasi panas yang direndam dalam minuman vodka, namun tidak terdapat perbedaan kekuatan transversal yang signifikan terhadap perendaman resin akrilik dalam minuman bir dan anggur merah. $^{2}$

Penelitian ini bertujuan untuk mengetahui perbedaan kekuatan transversal basis resin akrilik polimerisasi panas pada perendaman minuman beralkohol (cap tikus) dan aquades, serta untuk mengukur berapa besar kekuatan transversal basis resin akrilik polimerisasi panas yang direndam dalam minuman beralkohol dan resin akrilik yang direndam dalam aquades.

\section{BAHAN DAN METODE PENELITIAN}

Penelitian ini menggunakan metode eksperimental dengan rancangan post-test only control group design. Subjek penelitian ini adalah pelat resin akrilik polimerisasi panas merek QC-20 sebanyak 32 buah pelat resin akrilik yang berukuran panjang $62 \mathrm{ml}$, lebar $10 \mathrm{ml}$, tebal 2,5 ml. 
Minuman beralkohol yang dipakai dalam penelitian ini ialah minuman beralkohol cap tikus dengan kandungan alkohol $40 \%$ yang diperoleh dari agen resmi penampung cap tikus di Desa Tombasian Bawah Kabupaten Minahasa.

Pengujian kekuatan transversal menggunakan alat controls model 65L28Z10 universal testing machine di Laboratorium Teknik Sipil Fakultas Teknik Universitas Sam Ratulangi. Pelat Resin akrilik polimerisasi panas yang telah dibuat dari polimer dan monomer yang proses polimerisasinya dilakukan dengan menggunakan proses pemanasan dengan pemasakan dalam air $100^{\circ} \mathrm{C}$ selama 20 menit, dengan ukuran pelat $65 \times 10 \times 2,5 \mathrm{~mm}$ kemudian direndam dalam aquades selama 24 jam agar semua pelat dalam keadaan yang sama kemudian 16 pelat resin akrilik direndam dalam minuman beralkohol dan 16 pelat resin akrilik lainnya direndam dalam qauades masing - masing selama 8 hari kemudian masing-masing pelat diukur kekuatan transversalnya dengan menggunakan rumus:

$$
S=\frac{3 p l}{2 b d^{2}}
$$

Keterangan :

$\mathrm{S}$ : kekuatan transversal $(\mathrm{N} / \mathrm{mm})$

$\mathrm{p}$ : beban maksimal pada titik patah $(\mathrm{N})$

$\mathrm{l}$ : jarak pendukung (mm)

$\mathrm{b}$ : lebar spesimen $(\mathrm{mm})$

$\mathrm{d}$ : tebal spesimen (mm)

\section{HASIL PENELITIAN}

Rerata beban maksimal yang dapat diterima oleh pelat resin akrilik, rerata kekuatan transversal pelat resin akrilik dan hasil uji statistik Independent sample t-test. Berdasarkan Tabel 1 rerata beban maksimal yang dapat diterima setiap sampel yang direndam dalam aquades lebih besar yaitu 121,43 N dibandingkan dengan rerata beban maksimal yang dapat diterima setiap sampel yang direndam dalam minuman beralkohol cap tikus yaitu 108,68 N. Kelompok 1 yaitu kelompok perlakuan beban maksimal tertinggi diterima oleh sampel nomor 16 yaitu $128 \mathrm{~N}$ dan beban maksimal terendah diterima oleh sampel nomor 1 yaitu $92 \mathrm{~N}$, pada kelompok 2 yaitu kelompok kontrol sampel nomor 7 menahan beban paling tinggi yaitu $154 \mathrm{~N}$ dan sampel nomor 3 menahan beban paling rendah yaitu $106 \mathrm{~N}$.

Tabel 1. Rerata beban maksimal (Newton) yang dapat diterima setiap sampel dengan kecepatan crosshead $20 \mathrm{n} / \mathrm{s}$

\begin{tabular}{ccc}
\hline & \multicolumn{2}{c}{$\begin{array}{c}\text { Beban maksimal yang diberikan (N) } \\
\text { untuk kelompok sampel }\end{array}$} \\
\cline { 2 - 3 } Sampel & $\begin{array}{c}\text { Kelompok } \\
\text { Perlakuan }\end{array}$ & Kelompok Kontrol \\
\cline { 2 - 3 } 2 & 92 & 111 \\
3 & 125 & 137 \\
4 & 116 & 106 \\
5 & 106 & 115 \\
6 & 108 & 139 \\
7 & 105 & 116 \\
8 & 104 & 154 \\
9 & 106 & 113 \\
10 & 104 & 120 \\
11 & 113 & 108 \\
12 & 105 & 122 \\
13 & 94 & 108 \\
14 & 125 & 129 \\
15 & 110 & 138 \\
16 & 98 & 118 \\
Rerata & 128 & 109 \\
\hline
\end{tabular}

Tabel 2 menunjukkan rerata kekuatan transversal pelat resin akrilik setiap sampel pada kelompok perlakian dan kelompok kontrol. Berdasarkan hasil ini kelompok kontrol memiliki nilai rerata kekuatan transversal yang lebih tinggi yaitu 131,11 $\mathrm{N} / \mathrm{mm}^{2}$ dibandingkan dengan kelompok perlakuan yang memiliki nilai rerata kekuatan transversal sebesar 117,35 $\mathrm{N} / \mathrm{mm}^{2}$.

Berdasarkan hasil uji statistik independent sample t-test didapatkan hasil mean dari kelompok sampel minuman beralkohol cap tikus dengan 16 sampel sebesar 117,350 dan dari kelompok sampel aquades dengan 16 sampel didapatkan mean sebesar 131,112 dengan nilai $P$ value $=0,007(\mathrm{p}<0,05)$. Berdasarkan hasil ini dapat disimpulkan bahwa ada perbedaan kekuatan transversal antara pelat resin akrilik yang direndam dalam minuman beralkohol cap tikus dan pelat resin akrilik 
yang direndam dalam larutan aquades (Tabel 3).

Tabel 2. Rerata hasil uji kekuatan transversal pelat resin akrilik dengan kecepatan $20 \mathrm{n} / \mathrm{s}$ yang direndam dalam minuman beralkohol cap tikus dan aquades

\begin{tabular}{ccc}
\hline & \multicolumn{2}{c}{$\begin{array}{c}\text { Kekuatan trasnsversal pelat } \\
\text { resin akrilik }\left(\mathrm{N} / \mathrm{mm}^{2}\right)\end{array}$} \\
\cline { 2 - 3 } Sampel & Kelompok & Kelompok \\
& $\begin{array}{c}\text { Perlakuan } \\
\text { Kontrol }\end{array}$ & 119,8 \\
2 & 99,3 & 147,9 \\
3 & 135 & 114,4 \\
4 & 125,2 & 124,2 \\
5 & 114,4 & 150,1 \\
6 & 116,6 & 125,2 \\
7 & 113,4 & 166,3 \\
8 & 112,3 & 122 \\
9 & 114,4 & 129,6 \\
10 & 112,3 & 116,6 \\
11 & 122 & 131,7 \\
12 & 113,4 & 116,6 \\
13 & 101,5 & 139,3 \\
14 & 135 & 149 \\
15 & 118,8 & 127,4 \\
16 & 105,8 & 117,7 \\
\hline Rerata & 138,2 & 131,11 \\
\hline
\end{tabular}

Tabel 3. Uji statistik perbedaan kekuatan transversal pelat resin akrilik yang direndam dalam minuman beralkohol cap tikus dan yang direndam dalam larutan aquades

\begin{tabular}{cccl}
\hline Kelompok & $\mathrm{n}$ & $\begin{array}{c}\text { MEAN } \pm \\
\text { SD }\end{array}$ & $\begin{array}{l}\mathrm{P} \\
\text { value }\end{array}$ \\
\hline Minuman & 16 & $117,350 \pm$ & 0,007 \\
beralkohol & & 11,412 & \\
cap tikus & & & \\
Aquades & 16 & $131,112 \pm$ & \\
& & 15,183 & \\
\hline
\end{tabular}

\section{BAHASAN}

Hasil penelitian menunjukkan bahwa ada perbedaan kekuatan transversal pelat resin akrilik yang direndam dalam minuman beralkohol dan pelat resin akrilik yang direndam dalam aquades. Pelat resin akrilik yang direndam dalam minuman beralkohol cap tikus memiliki kekuatan transversal lebih rendah dibandingkan kekuatan transversal pelat resin akrilik yang direndam dalam aquades. Hal ini disebabkan sifat fisik resin akrilik yang mampu menyerap air sehingga partikel larutan dapat berpenetrasi dan mempengaruhi ikatan kimia resin akrilik. Semakin lama masa perendaman maka semakin banyak pula partikel larutan yang dapat berpenetrasi ke ruang mikroporositas resin akrilik. Molekul air dapat menembus massa polimetil metakrilat dan menempati posisi di antara rantai polimer sehingga rantai polimer ini memisah. Perpisahan rantai polimer ini dapat melemahkan struktur kimia resin akrilik. Kekuatan resin akrilik kemudian akan menurun karena sifatnya yang menjadi lebih plastis. ${ }^{5}$

Alkohol menyebabkan pembubaran polimer pada permukaan resin hingga menyebabkan retakan-retakan kecil atau carazing akibat dari difusi bahan. ${ }^{6}$ Pengaruh minuman beralkohol adalah menurunkan kekuatan resin akrilik untuk menahan beban. Aksi alkohol bersifat ganda yaitu menyebabkan efek crazing yang menurunkan kekuatan statik dan dinamik dari material dan menimbulkan efek kosorif pada permukaan gigi tiruan. ${ }^{7}$

Konsentrasi etanol pada minuman beralkohol yang dikonsumsi mempengaruhi sifat fisik dari resin akrilik dimulai dengan terjadinya pemisahan komponen resin unloaded pada permukaan resin akrilik untuk jangka waktu lama dan kemudian terjadinya efek crazing menyebabkan daya tahan gigi tiruan lebih rentan terhadap fraktur. ${ }^{8}$ Resin akrilik rentan terhadap larutan berkosentrasi tinggi seperti alkohol sehingga mempengaruhi daya tahan gigi tiruan terhadap fraktur diakibatkan oleh difusi bahan dan efek alkohol pada resin akrilik akan mengakibatkan menurunnya efek statis dan dinamis dan menimbulkan efek korosif pada resin akrilik dibandingkan dengan aquades. Ikatan hidrogen bisa terbentuk antar kelompok ester karbonil pelimetilmetakrilat dan hidroksil dari alkohol, energi pada ikatan berbeda untuk alkohol karena variasi dalam interaksi antar molekul member efek berlainan pada sifat mekanis bahan basis gigi tiruan resin akrilik. ${ }^{2}$ 
Hasil ini didukung oleh penelitian sebelumnya seperti pada penelitian oleh Umaiyal S (2011) mengatakan bahwa terdapat perbedaan yang signifikan terhadap kekuatan transversal yang direndam dalam minuman vodka namun tidak terdapat perbedaan kekuatan transversal pada resin akrilik polimerisasi panas yang direndam dalam bir dan anggur merah. Apabila mengkonsumsi alkohol dalam jangka waktu yang lama diduga akan me nurunkan kekuatan transversal bahan basis gigi tiruan resin akrilik polimerisasi panas yang digunakan sehingga akan mudah menyebabkan fraktur. ${ }^{2}$

Kandungan alkohol dalam minuman beralkohol melemahkan sifat fisik dan mekanik resin akrilik sehingga memengaruhi kekuatan transversal basis resin akrilik polimerisasi panas. Kekuatan transversal juga tergantung dari teknik pengadukan, kandungan monomer sisa, mikroporositas gigi tiruan yang tidak terlihat serta proses pembuatan resin akrilik hingga proses curing.

\section{SIMPULAN}

Berdasarkan hasil penelitian dapat disimpulkan bahwa terdapat perbedaan bermakna antara kekuatan transversal basis resin akrilik polimerisasi panas pada perendaman minuman beralkohol dan pada perendaman aquades.

\section{SARAN}

1. Bagi masyarakat pengguna gigi tiruan: agar gigi tiruan tidak mudah patah hindari mengonsumsi minuman beralkohol dalam jangka waktu panjang dan dengan kandungan alkohol yang tinggi sesuai peraturan pemerintah.

2. Bagi institusi: Perlu dilakukan penyuluhan dan edukasi kepada masyarakat mengenai efek minuman beralkohol yang dapat menyeabkan gigi tiruan mudah untuk patah.

\section{DAFTAR PUSTAKA}

1. Mayati NA. Pengaruh Larutan Ekstrak Daun Sirih (Piper Betle L) Terhadap Perubahan Warna Basis Resin Akrilik Heat Cured [skripsi]. Makassar: Universitas Hasanuddin; 2013. p.6 [cited April 2015].

2. Sockaligam U. Pegaruh Minuman Beralkohol Terhadap Kekuatan Transversal Bahan Basis Gigitiruan Resin Akrilik Polimerisasi Panas [skripsi]. Medan; Universitas SumateraUtara; 2011. p.1-3,15 [cited April 2015]

3. WHO. Global status report on alcohol. 2004. Available from: URL: http://www.who.int..substance [cited April 2015]

4. Wala S. Profil Usaha Pengolahan "Cap Tikus" di Desa Tokin Baru Kecamatan Motoling Timur. Jurnal ilmiah Fakultas Pertanian Universitas Sam Ratulangi 2013;vol.3: p.14-16 [cited April 2015]

5. Anusavice, Kenneth J. Phillips buku ajar ilmu kedokteran gigi. Trans. Johan Arif Budiman, Susi Purwoko. Lilian Juwono, eds. Edisi 10. Jakarta : EGC, 2003: 51-3, 52-1, 197-98

6. Kawagoe M, Ishimi T. On the properties of organic liquids affecting the crazing behavior im glassy polymers. (abstract) J Mat Sci. 2002;37: 511521.

7. Vlissidis D, Prombonas A. Effect of alcoholic drinks on surface quality and mechanical strength of denture base materials. Department of Prosthodontics, Dental School, University of Athens, Greece. Journal of Biomedical Materials Research 02/1997;38(3):257-61.

8. Regis RR, Soriani NC, et al. Effects of ethanol on the surface and bulkproperties of a microwaveprocessed PMMA denture base resin. Department of Dental Materials and Prosthodontics, School of Dentistry of Ribeirao Preto, Sao Paulo, Brazil J Pros. 2009;18:489-95. 